\title{
El léxico de tejidos en inventarios notariales del siglo XVII ${ }^{*}$
}

\author{
MARTA PÉREZ TORAL \\ Universidad de Oviedo \\ mtoral@uniovi.es \\ A mi madre, \\ que me enseñó el arte de telas y costuras
}

\section{INTRODUCCIÓN}

En este artículo realizaremos un estudio lingüístico de algunas voces que designan telas o tejidos usados en la confección del vestido y que hemos documentado en inventarios notariales manuscritos del siglo XVII. Nuestra principal fuente de documentación es el Corpus Léxico de Inventarios (CorLexIn) ${ }^{1}$, que reúne en estos momentos casi medio millar de documentos originales e inéditos del ámbito peninsular con más de un millón de formas, aunque también algunos ejemplos proceden de textos leídos que aún no se hallan incluidos en el mencionado corpus. Es evidente que este estudio se centra en un grupo concreto de documentos y, por ello, las conclusiones de él derivadas podrían verse matizadas con la lectura o incorporación de otros textos.

En otras ocasiones (Peréz Toral 2008, 2013 y 2015) ya pusimos de manifiesto la importancia y valor de los textos notariales para la lexicografía histórica: inventarios, testamentos, hijuelas, tasaciones, almonedas, etc., son textos en los que los escribanos suelen detallar y describir con exactitud enumeraciones de bienes, lo que nos permite tener una visión bastante precisa y real del léxico de la época; y entre ese léxico, constatamos una notable presencia de voces referidas a los diferentes tipos de tejido de los ajuares que se inventarían ${ }^{2}$.

Sobre el léxico textil existen estudios lingüísticos realizados desde diferentes perspectivas: alguno centrado, total o parcialmente, en la referencia toponímica del significante (García Fernández 2004, Morala 2010), otros, en el análisis de voces textiles en una determinada época, medieval (Alfau de Solalinde 1969, Martínez Meléndez 1989, Vicente Miguel 2009), renacentista (Sánchez Orense 2008, 2010 y 2012), siglo XVII (Morala, 2010, Pérez Toral 2017a y b) o XVIII (Stala 2014), entre otros.

* Para la realización de este trabajo se ha contado con la financiación del Ministerio de Economía y competitividad y del Fondo Europeo de Desarrollo Regional al proyecto con número de referencia FFI2015-63491-P (MINECO/FEDER).

${ }^{1}$ El corpus está alojado en la web de la Fundación Rafael Lapesa, junto a otros materiales de consulta del $C D H E$, y disponible en $<$ http://web.frl.es/CORLEXIN.html>.

${ }^{2}$ Estos tejidos presentan distinta fisonomía dependiendo del tipo de textura, que resulta de la conjunción de la trama y la urdimbre, es decir, de la técnica empleada y de la materia prima o fibra empleada, que puede ser animal, como la lana o la seda, y vegetal, como el lienzo, el algodón o el lino.

MARTA PÉREZ TORAL,

«El léxico de tejidos en inventarios notariales del siglo XVII», Revista de Lexicografia, XXIII (2017), pp. 157-184 ISSN: 1134-4539, e-ISSN: 2603-667. doi: https://doi.org/10.17979/rlex.2017.23.0.4701 
Para nuestro trabajo hemos seleccionado unas cuantas palabras, la mayoría designan telas hechas a partir de lana, alguna con seda y en menor medida con algodón o lino; una vez más se confirmaría que en esta época áurea la materia prima básica sigue siendo la lana, combinada en ocasiones con seda o con algodón ${ }^{3}$.

De estas voces objeto de estudio, incluidas en textos notariales del siglo XVII, queremos analizar el significado de cada una de ellas, así como su distribución geográfica en cuanto al uso, las posibles variantes, la información que sobre cada vocablo recogen las fuentes lexicográficas consultadas, su origen y la primera documentación registrada teniendo en cuenta otros corpus y estudios sobre el tema; sin olvidar la vigencia de cada palabra a lo largo de los siglos.

\section{ANASCOTE}

El $D L E$ define esta voz como «tela delgada de lana, asargada por ambos lados, que usan para sus hábitos varias órdenes religiosas. También la emplean para sus vestidos las mujeres del pueblo en algunas provincias de España»e incluye una segunda acepción, en desuso, como «tela de seda, parecida a la sarga». Dávila et alii (2004) aportan una tercera definición: «tejido de algodón fino, resistente, tupido, de color generalmente negro, que servía para fajas, jubones, zapatos, vestidos de luto, etc.» y por último García Fernández (2004: 138) especifica «tejido de estambre asargado muy consumido en España».

Los ejemplos que nos proporciona nuestro corpus CorLexIn se extienden por toda España y así de la variante anascote obtenemos más de un centenar de ocurrencias casi todas ellas referidas a manto, lo que nos permite considerar que en la mayoría de los documentos esta voz refiere un tejido hecho con lana:

Ytten, vna ropa muy bieja de anascote, negra. Yten, vna saya de estameña açul con sus corpiños, vieja. Ytten, vn sayuelo negro de anascote muy traído (Tolosa, SS-1633)

Vna capa serrada de anascote, seis ducados (Bilbao, 1645)

Más dos debantales, uno de paño negro y otro de anascote negro (Deusto, Bi-1643)

Yttem, otra ropa capona de anascote, bieja. (Tudela, Na-1641)

Yten, vn manto de anascote viejo para la moza. Yten, vn manto de anascoste (sic), nuebo, de luto. Yten, vna saya grande de anascote, nueba. Yten, vnas mangas de anascote, de luto, nuebas (Cuenca, 1622)

Dos mantos de anascote, en doçientos reales (Albacete, 1642)

Vn manto de anascote en quarenta y quatro reales (Cartagena, Mu-1640)

Vna basquiña vssada de anascote blanco, en veinte y cinco reales (Sax, A-1661)

Zinco baras y media de anascote blanco en tres pedaços (Medina de Rioseco, Va-1645)

Yten, vn bestido negro de anascote de muger [...] y ropilla de anascote negro (Sevilla, 1640)

Jubón de anascote, en çien reales (Sevilla, 1669)

Yten, un jubón de muger de anascote, en dies y ocho reales (Huelva, 1634)

Vn manto de anascote a medio traer, veinte reales (Baza, Gr-1660).

También hallamos, en menor número, las variantes anescote y aniscote:

Yten declaro que ansí bien tengo en enpe[ño] en mi poder una saya açul, de anescote (Bilbao, 1643)

Vn manto de anescote a medio andar (Herrera de Valdecañas, Pa-1700)

\footnotetext{
${ }^{3}$ Al igual que ocurría en la Edad Media y Renacimiento (Sánchez Orense 2010: 415).
} 
Vn manto de aniscote, vna mante[1lina] de burato, vna saia de sempiterna de color [a]musco oscuro, otra saia de estameña parda, otra saia de aniscote biexa (Alzaga, SS-1693).

Y Morala (2010: 389) cita también la variante anescote: «un manto de anescote nuevo» (Santo Domingo de la Calzada, 1647).

En cuanto a la procedencia de esta voz, Rosal en su Origen y etimología de todos los vocablos de la Lengua Castellana de 1611, proponía que anascote era el resultado de «dos palabras lana scotos. Lana porque lo es y perdió la $l$-; scotos en griego es cosa negra o parda; que comúnmente es de este color». No obstante, hoy existe unanimidad en que anascote procede del francés antiguo anascot, y este de Hondschoote, ciudad flamenca (DLE; García Fernández 2004:138; Morala 2010: 389 y 2014: 259; y Stala 2014: 197; entre otros); y más concretamente el $D E C H$ explica que la forma de Lieja hanscote, con $h$ aspirada, prueba que se trata de un derivado de ese topónimo.

Diacrónicamente, el término anascote no se documenta en el medievo: Martínez Menéndez (1989) no lo recoge en su estudio sobre los nombres de tejidos en castellano medieval y tampoco lo registra Alfau de Solalinde (1969) en textos del siglo XIII. Según el $D E C H$ la primera documentación de anascote se hallaría en las Ordenanzas de Sevilla de 1527 y el $C D H$ la localiza unos años más tarde en 1563:

Anascote á trescientos cincuenta maravedís... 3,500 (Valuación hecha en la villa de Bilbao del precio de las mercaderías que venían de fuera del Reino, 1563).

Mientras que el CORDE lo retrasa a 1580 :

Yten, mando a Mari Ruiz y a su hermana, a cada una de ellas un monjil nuevo de anascote porque rrueguen a Dios por my anima (Testamento de Juan de Barrientos, mercader, 1580).

En el siglo XVII se produce un notable incremento de ejemplos recogidos en el $C D H$ y en el CORDE, todos ellos con la acepción de 'lana' y referidos casi siempre a manto o capa y en menor número a traje, jubón, saya, fardel, sotanilla, ferreruelo, calzas, y solo en una ocasión a cortinas.

A la luz de todos nuestros datos, podríamos considerar que la voz anascote, casi siempre con el significado de 'tejido de lana', inicia su andadura en el primer tercio del siglo XVI y se extiende por toda la geografía peninsular a lo largo del siglo XVII, para decrecer en las centurias siguientes.

\section{BARRAGÁN}

Yten, vn corte para un capote, de varragán (Lumbreras, LR-1685)

Bestidos: Vn capote de barragán como nuebo, musco. Vn coleto de ante. Vn capote de barragán muy biexo, platedao (Lumbreras, LR-1688)

Un capotón de barragán, forrado en baeta, en setenta reales (Puebla de Peñarubia, Teba, Antequera, Ma-1699).

El DLE explica también que esta voz procede del árabe hispano bar[ra]kán[i], este del árabe barkānī 'tipo de paño negro indio', y este del persa pargār o pargāl; y el $D E C H$ propone el étimo barrakân, con una primera documentación en unos aranceles santanderinos del siglo XIII (Castro 1921). 
Martínez Meléndez (1989: 28-30) recoge las variantes latinizadas barraganorum y barracenorum ${ }^{4}$ ambas en el Fuero de Cuenca (1272-1296) y en el Fuero de Zorita de los Canes (fines del XIII o principios del XIV) y la forma baragán ${ }^{5}$ también en documentos santanderinos de finales del siglo XIII. Afirma también que desde principios del siglo XIV no hay testimonios de barragán con el significado de tejido en documentos castellanos. Dicha ausencia se confirma con los datos que nos ofrecen algunas bases de datos.

Para el $C D H$ la primera documentación de barragán es de finales del siglo XIII:

Veynte sayas de estanfortf e de barragan (Fuero de Alcaraz, 1296).

Más allá de este siglo no recoge ejemplos hasta el XVII donde aparecen algunos casos esporádicos de capote de barragán, a partir del XVIII el uso es exiguo, como muestra este significativo ejemplo donde se relacionan una serie de productos que se envían a América:

Productos enviadosa América: paños de Louviers, moletones, franelas, telas groseras y finas e seda (fleurettes y florences), tafetanes, holandillas, paños finos de Inglaterra, hilos, calcetas, medias de estambre, mantos, buratos, encajes de seda, sedas, encajes de oro, galón de oro, cambrays, cambrayones, lienzos crudos, roanes, bretañas, blancantes, [...], bayetas, anascotes, escarletines, barraganes, palometas, estameñas, picotes, brocados (Esteban Terradas, Neologismos, arcaísmos y sinónimos en plática de ingenieros, 1946).

Por su parte el CORDE propone como primera documentación el año 1300, de ahí pasa al siglo XVIII con cuatro casos, cinco en el XIX y uno en el XX:

De la pieça de barragan, de ysembrun, de bruja \& de raz, .VIII. dineros (Fuero de Bae$z a, 1300)$

Chupasotana apuntalada con zoquetes de barragán de tumbas, que los químicos llaman panno exequiarum y nosotros bayeta de lutos (Diego de Torres de Villarroel, Visiones y visitas de Torres con Don Francisco de Quevedo por la corte, 1727-1728)

Y á mas de esto varias piezas de cordellate y barragan para el uso del pueblo (José Antonio Cavanilles, Observaciones sobre la historia natural, geografia, agricultura, población y frutos del reyno..., 1795).

Esta falta de testimonios de la voz barragán a lo largo del siglo XIV hasta el XVIII se confirma una vez más con la revisión de los repertorios lexicográficos, pues no aparece registrada hasta 1726 en el Diccionario de Autoridades como «género de tela hilada sutilmente, y hecha de lana de diferentes colores: su ancho poco menos de vara».

\section{BEATILLA}

Beatilla se define como «especie de lienzo delgado y ralo» en el $D L E$ y como «tela de lino, delgada, clara y rala, con la que se hacían tocas transparentes, a modo de velo o mantilla» en Dávila et alii (2004); asimismo estos proponen una segunda acepción «mu-

${ }^{4}$ «De barraganorum, ysembrunorum, bruiarum et arracensium, octo denarios»; «Viginti sayarum stamfort, barracenorum aracensium et brullarum faciunt troxellum» (Fuero de Cuenca y Fuero de Zorita de los Canes), en Martínez Meléndez (1989: 28).

5 «Baraganes de Roan $\tau$ de beluas $\tau$ de Loherens $\tau$ de Prouins» (Aranceles), en Martínez Meléndez (1989: 28). 
selina o tejido de algodón blanco fabricado en las Indias Orientales, en particular en Pondichery» y especifican que existían tres variedades: la beatilla simple, un poco grosera; la conocida como organdí, por su grano redondo y su finura; y la tarnatana, muy clara.

El CorLexIn reúne un gran número de ejemplos documentados en inventarios de toda la geografía peninsular:

Yten, dos baras de beatillas y vn paño de color listado (Ribadesella, Ast-1599)

Vna tela de sobarbios, que serán veinte y seys baras de beatillas, poco más o menos (Cuerres, Ribadesella, As-1622)

Una tela que se está texiendo en casa de María Fon, la Baluina, de beatilla (Oviedo, Ast1634)

Quatro baras de lienzo de zerro, como beatilla (Tanos, C-1674)

Yten, vna cama de beatilla, cortinas y cielo con su flueco blanco, en seis pieças. Yten, dos beatillas de caueça (Oñate, SS-1617)

Tres toallas de beatilla delgada. [...] Tres gorgueras de beatilla. [...] Seis camisas de muger de veatilla cortadas, sin coser. [...] Treinta uaras de veatilla. Otro dos pedaços de beatilla (Vergara, SS-1632)

Yten otra sáuana de beatilla, de nuebe baras, de balor de diez y ocho reales (Arrigorriaga, Bi-1638)

Tres cubiertas de beatillas para tres corporales. Ocho purificadores de beatilla nueuos (Vicuña, Vi-1640)

Dos tocas de veatillas buenas (Matueca de Torío, Le-1643)

Yten vn peinador de hacer la barba, de veatilla con puntas (Solanilla, Le-1662)

Yten otro taleguillo y en él otra pelliz de beatilla (Solanilla, Le-1662)

Una cofia de beatilla nueba (Villalobos, Za-1654)

Nueue varas de veatilla, de media cara de ancho (Zaragoza-1647)

Yten, otro reboço de beatilla, en tres reales (Revilla del Campo, Bu-1639)

Yten unos paramentos de cama y de beatilla, listados y con encajes blancos (Santurde, LR-1666)

De beatilla portuguessa, veinte y tres varas, a real y medio (Atienza, Gu-1640)

Un peinador de beatilla con unas puntas pequeñas (Bercial de Zapardiel, Arévalo, Av1650)

Y dos gorgerillas de beatilla. Yten, vn tocador de beatilla nuevo (Cuenca, 1622)

Dos peynadores de beatilla, de tocar, llanos. Vna camisa, de beatilla las faldas y el cuerpo de lienço, labrada de negro (Madrid, 1649)

Quatro toallas de beatilla pequeñas, llanas, de Vizcaya. Otras dos toallas mayores de beatilla de Vizcaya, grandes, sin guarniçión. Dos toallas de beatilla de Vizcaya, labradas medianas. Otra toalla de beatilla de Vizcaya, grande, labrada (Madrid, 1649)

Quatro baras de beatilla. Alcalá la Real (Jaén, 1648)

Más, vnos manteles de altar de veatilla con puntas y tres pieças de almoadas con sus ajedrezados (Sevilla, 1650)

Yten, dos pares de naguas de beatillas en dies pessos (Cádiz, 1655)

Yten, cada piesa de veatilla fina catorze reales de plata que hazen (Huelva, 1691).

Por su parte Egido (2010: 96-97) también recoge ejemplos del siglo XVII de beatilla, y su variante biatilla ${ }^{6}$, en las zonas leonesas de Maragatería, Cepeda y Órbigo:

${ }^{6}$ Bernis (1962: 77) también halla la variante biatillas en un inventario de 1546: «Biatillas travelladas blancas, de glosa y de cotó de seda». 
Dos tocas de muxer de fiesta de beatilla (Quintanilla de Sollamas, Le-1612)

Mas tres tocas de biatilla de oviedo [...] y una de espomilla (Llamas de la Ribera, Le1668).

Dos tocas de beatilla mas una de bolbedera (Riego de la Vega, Le- 1679).

De dicha variante hallamos dos casos en un inventario riojano:

Unos paramentos de biatilla, con su red enzima a la cama, andados (Briones, LR-1650)

Dos maseras de orno, una de biatilla y otra de cáñamo, andadas (Briones, LR-1650).

Asimismo, este término se utiliza también como sustantivo con el significado de «las tocas que se hacían con esa tela», como en estos ejemplos que nos ofrece nuestra base de datos:

Yten, dos beatillas de caueça (Oñate, SS-1617)

Dos beatillas nueuas, en dos ducados. Otro tocado que llaman tocón de Balençia, en ocho reales. Otro algodón nueuo, en seys reales. Otras dos beatillas de Obiedo, bastas, en diez reales (Sahagún, Le-1601)

Yten una veatilla fina, en doze reales (Medina de Rioseco, Va-1643)

Yten, otras tres baras de lienço para beatillas, sin mojar (Tafalla, Na-1641).

Y tampoco faltan casos en los que la voz beatilla funciona como adjetivo sin preposición intermedia:

Yten, en vna de lienço beatilla de la tierra, que se medió: hay beinte y tres baras (Tolosa, SS-1633)

Yten, vn tocado beatilla con su encaxe i puntas apreziado en cuatro ducados. Yten, otro tocado beatilla con una franxa de oro apreçiado en diez y seis reales (Ventosa de la Cuesta, Va-1610)

Vna toca beatilla (Nava del Rey, Va-1648).

En cuanto al origen de esta voz, Covarrubias (1611) considera que «debió ser invención del tipo de hilado y tela utilizada por las beatas para taparse la cabeza cuando iban a las funciones religiosas, o porque la usaban las mujeres recoletas que no se engalanaban». Y el $D E C H$ propone una etimología a partir del latín BEATUS y señala como primera documentación de beatilla el año 1496.

El resto de propuestas para la documentación más temprana apuntan todas al siglo XVI, así Bernis (1962: 77) considera que el primer testimonio de esta voz se encuentra en un inventario toledano de la primera mitad del siglo XVI:

Los pedaços de beatilla de biscaya que tienen onze varas e media (Inventario de las ropas y alhajas de la sra. Emperatriz, 1539).

Señala también que quizá en España esta voz sea de importación portuguesa ${ }^{7}$, dado que en el país vecino se documentan numerosos ejemplos de beatilla desde 1493.

Por su parte el CORDE nos proporciona siete ejemplos, el más temprano del siglo XVI, otro del XVII y el resto del XVIII:

${ }^{7}$ Bernis propone (1962: 77) este ejemplo del portugués Jorge de Montemayor: «Todas venian vestidas de beatillas blancas delicadas, tejidas con plata y oro sutilísimamente» (Los siete libros de Diana, 1559). 
Hirióse con algún alfiler de la beatilla en él (Francisco Sánchez de las Brozas, Comentarios a Garcilaso, 1574).

Y el $C D H$ solo reúne estas dos ocurrencias de los siglos XVII y XVIII, respectivamente:

Y pensaron que habían hilado, beatillas (Francisco López de Úbeda, La pícara Justina 1605)

En la pretina por el lado derecho, colgado un pañuelo de beatilla con mucha gracia (José Francisco de Isla, Historia del famoso predicador Fray Gerundio de Campazas alias Zotes, 1758).

Con todos estos datos y el análisis realizado, podríamos concluir que su uso podría haberse iniciado en la segunda mitad del siglo XV, uso que alcanzaría su expresión máxima en el siglo XVII, para posteriormente ir decreciendo.

\section{BURATO}

El $D L E$ lo define como «tejido de lana o seda que servía para alivio de lutos en verano y para manteos» y Dávila et alii (2004) especifican: «estofa ligera, de tacto áspero, fabricada en Francia y Alemania, medio seda y medio lana, buscada por su larga duración y calidad».

Ya el Diccionario de Autoridades en 1726 recoge dos acepciones: «cierto género de texido delgado de lana, cuyo tacto es áspero» y «el que se hace de seda a semejanza del de la lana, el qual también es algo áspero al tacto».

Nuestra base de datos CorLexIn nos ofrece una veintena de ejemplos, la mayoría referidos a manto o capa:

Vna mante[1lina] de burato (Alzaga (SS-1693)

Vna capa de coro de burato, biexa. Otra capa de coro de burato, vn poco mexor (Burgo de Osma, So-1612)

Seis pieças de buratos de Milán, a cinquenta y dos reales pieça (Medina de Rioseco, Va1645)

Vn manto de burato, dos ducados y medio (Caravaca de la Cruz, Mu-1654)

Un ferreruelo de burato, negro. Montefrío (Granada, 1661)

Vn manteo y sotana de burato biejo (Montefrío, Gr-1662)

Más, vn ferreruelo de burato fino (Sevilla, 1650)

Y vn bestido de burato de muxer (Sevilla, 1650)

Dos ferreruelos de honbre, uno de adúcar y otro de burato, traídos, en zien reales (Jaén1650)

Vn jubón de mujer de burato (Alcalá la Real, J-1648)

Ytem, otra capa de burato, en quatro reales (Málaga, 1651).

En cuanto al origen, no existe unanimidad: el $D L E$ considera que procede del italiano buratto y el $D E C H$ del francés a partir de burat, con una primera documentación en un texto oscense de 1595; fecha que adelantaremos a 1568 gracias al siguiente ejemplo recogido en el $C O R D E$ y en el $C D H$ :

Dos mantos de burato de seda (Donación de Juan Francisco Locadelo en favor de Doña Andrea de Cervantes, 1568). 
De los datos expuestos, se desprende que no existe documentación escrita que certifique el uso de burato antes de mediados del siglo XVI, ni Martínez Menéndez (1989) ni Alfau de Solalinde (1969) lo registran en el medievo. La voz burato centraría su uso mayoritario en el siglo áureo, para reducirlo considerablemente en el XVIII ${ }^{8}$, hasta casi desaparecer en las centurias siguientes.

\section{Chamelote}

El $D L E$ lo registra con el significado de «tejido fuerte e impermeable, generalmente de lana» y Dávila et alii (2004) recogen chamelote y camelote como «tejido fuerte e impermeable que antes se hacía con pelo de camello, y después con el de cabra de Armenia, fabricado en Famagusta, Alepo y en el Kurdistán. También tela hecha de pelo con mezcla de lana, seda o hilo, o enteramente lana peinada». Consideran que este tejido empezó a fabricarse en Europa con lana o con mezcla y, aunque no existía fabricación en España, sí se usaba para la confección de vestidos de verano y solía llamarse orleans. A partir del siglo XIII, en Italia empezó a tejerse este textil con pelo de seda y en colores, cuyo resultado sería muy similar al tafetán o al tabí.

La base de datos CorLexIn nos facilita un buen número de ocurrencias de norte a sur de la península:

Otra sotanilla de chamelote viexa (Villamuñío, Le-1633)

Otra casulla negra, de chamelote de lana, con estola, manípolo y bolsa, negro (Santander, 1676)

Ytten, vnas mangas de chamelote negro, traídas (Tolosa, SS-1633)

Yten, vn vestido de chamelote de aguas guarnecido (Vitoria, 1638)

Yttem, veinte y cinco baras y media de chamelote de agua, negro (Tudela, Na-1641)

Ytem, otra casulla de chamelote berde de aguas con çenefa bordada (Panticosa, Hu1688)

Ropilla,calçón y talí de chamelote de lana (Zaragoza, 1647)

Yten, otro guardapiés de chamelote, color de violeta, con su encaje pequeño de oro y su forro (Lumbreras, LR-1685)

Más ocho varas y una quarta de chamelote noguerado, a seis reales bara (Medina de Rioseco, Va-1645)

Calçón y ropilla de chamelote negro. Jubón de chamelote azul (Madrid, 1650)

Vn vestido de muxer, vasquiña, jubón y ropa de chamelote de aguas negro (Argamasilla de Calatrava, CR-1662)

Ottra sotanilla de chamelote trayda (Atienza, Gu-1642)

Vna almilla de chamelote açul en cinquenta reales (Caravaca de la Cruz, Mu-1654)

Basquiña, jubón y ropa de chamelote negro de seda (Badajoz, 1653)

Ytten, vna basquiña de chamelote y vna mantellina de baieta, tres libras (Orihuela, A-1717)

Vn tapapiés de chamelote azul, en tres ducados (Cabra, Co-1664)

Más, vna ropa y jubón de damasco negro antiguo y vna ropa de chamelote negro. Más, vna basquiña de chamelote noguerado (Sevilla, 1650)

Vm bestido de chamelote de yerbas, pollera y jubón (Andújar, J-1665)

Vna basquiña de chamelote blanquisca (Huelva, 1673)

Vn guardabajos de chamelote, açul çeleste (Baza, Gr-1662)

${ }^{8}$ Stala (2014: 199) también la recoge en su Waaren-Lexicon in Zwölf Sprachen de 1797. 
Yten, vn guardapiés de chamelote de lana, encarnado (Almería, 1659)

Una sobrecama y rodapiés de chamelote asul de lana (Arcos de la Frontera, Ca-1666).

Explica el DECH que chamelote es palabra propagada en romance desde Francia y variante de camelot; del francés antiguo camel 'camello'. La palabra francesa camelot se halla desde 1248 y la catalana camelot desde 1287.

En español el ejemplo más antiguo es del siglo XV y lo recogen el CORDE y el $\mathrm{CDH}$ :

Que lo cubriese de paños blancos de chamelote (El baladro del sabio Merlín con sus profecías, 1400-1498).

Además el $C D H$ añade otros dos casos del primer tercio del siglo XV:

Los cabellos de las cabras del Galaad, que de ellas e de aquella lana se fazian os finos chamelotes (Mosel Arragel de Guadalfajara, Traducción y glosas de la Biblia de Alba II, 1422-1433).

El CORDE también nos proporciona cinco casos de la forma dialectal camelote a partir del siglo XVIII:

En verano la casaca era de camelote ceniciento (Conde de Fernán Núñez (Carlos Gutiérrez de los Ríos), Vida de Carlos III, c1790).

Y el $C D H$ recoge variantes como camelote, chamellote, jamelote y chamelot:

Que las dichas pieças de chamellote y alcantiffas sean restituydas a los sobredichos nuestros subditos (Fernando al rey Fernando de Nápoles..., 1495)

Primo hun sayon de jamelote y hun sayuelo de chamelot (Pedro del Ponte (Aponte), pintor y los tutores de sus hijas..., 1510)

En verano la casaca era de camelote ceniciento; la chupa, de seda azul con galón de plata, y el calzón el mismo (Conde de Fernán Núñez (Carlos Gutiérrez de los Ríos), Vida de Carlos III, 1790).

En la lexicografía española chamelote no aparece hasta 1611 en el Tesoro de la lengua castellana o española de Covarrubias, que lo define como «la tela hecha de pelo de camellos, quasi camelote, à camelo»; chamelot, jamelote, chamellote no se registran. Por su parte Terreros y Pando (1786) distingue chamelote de aguas, chamelotina y chamelotón, todas ellas con la acepción de 'tela gruesa y basta'.

En definitiva, parece que la época de mayor uso de esta voz es el siglo XVII, posteriormente decrece considerablemente el número de ocurrencias facilitadas por las bases de datos.

\section{CORDELlate}

Se trata de un «tejido basto de lana, cuya trama forma cordoncillo» (DLE). Dávila et alii (2004) aportan dos definiciones: «paño delgado como la estameña o tejido basto de lana que tenía el hilo de la trama más grueso que el de la urdimbre, de manera que al tejer la tela formaba como cordoncillo» y «tejido tupido y fuerte, que tenía la urdimbre de cáñamo y la trama de lana ordinaria o de cáñamo». 
Esta tela parece que se usó bastante para la confección de calzas, sayas, capirotes, mantillas, etc. Y prueba de ello es el gran número de ejemplos que hallamos en el CorLexIn distribuidos por todo el este peninsular:

Tres cortinas, las dos de perpetuán y otra de cordellate berde (Vergara, SS-1632)

Yten, unas medias de cordellate negras, dos reales, 68 maravedís (Vitoria, 1638)

Más vnas medias biejas, de cordellate (Torquiendo, Guriezo, C-1669)

Dos mantillas, vna de cordellate e lana y otra de lino e lana (Sahagún, Le-1601)

Vn cobertor viejo y muy [...]do, de cordellate (Herrera de Valdecañas, Pa-1700)

Yttem, vn mantico de cordellate blanco (Tudela, Na-1641)

Dos paños de cama viejos, de cordellate blanco (Zaragoza, 1647)

Vn jergón, once colchones, vn papellón de cordellate verde (Huesca, 1654)

Unas calças de cordellate buenas, coloradas Aguilafuente (Segovia, 1623)

Yten, se remató en Catalina Terer una mantilla de cordellate blanco en once reales y quartilo (Ólvega, So-1638)

Yten, otra sobrecama berde de cordellate, vieja, de tres piernas, sin flecos y pequeña (Cuenca, 1622)

Dos pares de henag[u]as, vnas de cordellate pagiças (Atienza, Gu-1641)

Más, vnas enaguas açules de cordellate, biejas. (Madrid, 1648)

Otro paño açul de colgar de cordellate (Lillo, To-1627)

Ytem, una saya de cordellate azul mediada (Teruel, 1652)

Vn cobertor de cordellate colorado en quarenta y quatro reales (Cieza, Mu-1661)

Vna almilla de cordellate colorada, en doce reales (Sax, A-1661)

Vn capotillo encarnado, de cordellate, con guarniçión pajiça (Baza, Gr-1662).

Morala (2010: 390) menciona también la variante cordellate de Aragón de la que documenta un único ejemplo en un documento toledano:

Unas enaguas de cordellate de Aragón colorado (Escalona, To-1644).

Y Stala (2014: 202) recoge en su Lexicon la variante cordelleta que no aparece ni en el CORDE ni en el $C D H$ ni en la lexicografía española.

En cuanto a la primera documentación de esta voz no existe unanimidad, aunque es Martínez Meléndez (1989: 65-66) quien propone la fecha más temprana, concretamente 1442-1444:

Vara de cordellate angosto colorado (Torres Fontes 1968).

Tanto el CORDE como el $C D H$ reúnen un buen número de casos desde el siglo XV con un importante incremento en el XVI y XVII y una disminución considerable a partir del siglo XVIII, y proponen como fecha más temprana de aparición el año 1462:

Otrosy, la vara del cordellate blanco, común, grueso, a dies e ocho maravedís (Arancel de precios y salarios de Cuenca. Documentos sobre industria textil, 1462).

Por último el $D E C H$, que retrasa la fecha hasta 1511 , considera que esta voz procede del catalán cordellat, derivado de cordell.

Gracias a toda esta documentación parece probado su uso desde las postrimerías de la Edad Media. Alfau de Solalinde (1969) no lo incluye entre los tejidos españoles del medievo y en la lexicografía española no aparece hasta Covarrubias (1611) que lo defi- 
ne como «cierta especie de paño delgado, como estameña, dicho así por un cordoncillo que hace la trama».

\section{CREA}

El DLE recoge únicamente crea como «lienzo entrefino que se usaba mucho para sábanas, camisas, forros, etc.» y Dávila et alii (2004), que coinciden en esa definición, añaden «también se llamaban creas leonas por proceder de la ciudad de Léon (Bretaña, Francia)».

Nuestra base de datos CorLexIn nos facilita una larga lista de ejemplos, la mayoría localizados en Andalucía:

Otras dos sábanas, la una de crea y la otra con randa (Santander, 1676)

Yten dos camissas de muger, de crea, que tienen diez y seis baras (Arrigorriaga, Bi1638)

Dos paños de crea para los atrilles del Ebangelio, y leçión epístola (Vicuña, Vi-1640)

Yten, ocho almuadas casi nuebas, de olanda. Yten, otras diez y seis muy buenas de crea (Lumbreras, LR-1685)

Otra camisa de crea nueua, en beinte y seis ducados (La Solana, CR-1651)

Ytem, dos seruilletas de crea con [...] en siete reales, nuebas (Sax, A-1685)

Dos sáuanas de crea ancha en ziento y diez reales (Totana, Mu-1659)

Dos toallas de crea, en dies reales uellón (Alcalá de Guadaíra, Bengila, S-1718)

Yten, se apreciaron dos almodas de crea, basías, con sus faxas labradas de hilo azul

fino (Alcalá de los Gazules, Ca-1642)

Dos sábanas de crea cordelera nuebas (Andújar, J-1665)

Una camisa de mujer de crea estrenada en dos ducados (Cabra, Co-1664)

Vn paño de crea con sus puntas y desilados, de rostro (Canjáyar, Al-1646)

Quatro sábanas de lienso y crea (Huelva, 1608)

Tres calçones de crea biejos (Montefrío, Gr-1662).

El $D E C H$ defiende un origen francés, a partir del antiguo crée 'cierto lienzo de Bretaña' y este del bretón krés 'camisa' y propone como primera documentación 1621, pero Martínez Meléndez (1989: 534) la adelanta a 1402, pero ella hace referencia a la variante crera, que documenta en un inventario aragonés «Dos lencuelos de crera», variante que no aparece en ningún estudio ni diccionario y que el $D E C H$ considera que no procede de crea.

Por su parte, el $C D H$ no lo recoge y el $C D H$ sitúa el primer caso de crea en el primer decenio del siglo XVII:

Y medio; la onza de seda floja y torcida, peso y medio; la vara de terciopelo de la China, cinco y seis pesos; la de ruan, diez reales ó un peso; la de crea, seis reales (Descripción de los pueblos de la provincia de Panuco..., 1606-1610).

Rosal, en su Origen y etimología de todos los vocablos de la Lengua Castellana (1611), la define como «suerte de lienzo. Traxo el nombre de la tierra donde se labra en la India de Portugal», pero desde el Diccionario de Autoridades (1729) la definición se concreta teniendo en cuenta su procedencia real: «cierto género de tela ò lienzo, que no es de los mas finos ni de los mas toscos, que sirve para hacer camisas, sábanas y otras cosas. Llámase comunmente Leóna, porque viene de Leon de Fráncia». 
Nuestra base de datos CorLexIn reúne unos pocos ejemplos de la variante crea leo$n a$, todos en documentos notariales andaluces:

Vnos calçones de crea leona, en veinte reales (Andújar, J-1665)

Más, una camisa de crea leona labrada con seda negra (Andújar, J-1665)

Vna camisa de hombre com balona y puntas de Flandes de crea leona, quarenta y siete reales (Andújar, J-1665)

Quatro almohadas de crea leona con sus randas y listones en çinquenta y seis reales (Cabra, Co-1664)

Dos almohadas de crea leona, en treinta y tres reales (Teba, Antequera, Ma-1699)

Dos sábanas de crea leona con sus puntas, en siento y beinte y nuebe reales (Teba, Antequera, Ma-1699)

Otra toalla de crea leona, con puntas de pita, en tres ducados (Trigueros, H-1676).

Desde un punto de vista diacrónico, de la secuencia crea leona no tenemos más documentación que los ejemplos del siglo XVII facilitados por nuestra base de datos y la referencia lexicográfica de Autoridades en el mismo siglo.

\section{ESPARRAGÓN}

El $D L E$ lo define como «tejido de seda que forma un cordoncillo más doble y fuerte que el de la tercianela» y Davila et alli (2004), que coinciden con esta definición, aportan una segunda acepción «tejido o tela de lana, barragán ordinario o paño de baja calidad, fabricado en Inglaterra (Dirección general de rentas, $\left.1780^{9}\right) »$.

El CorLexIn nos proporciona una decena de ejemplos localizados de norte a sur:

Más vnas enaguas de esparragón, ochenta y quatro reales (Bilbao, 1645)

Seis varas y media de esparragón liso en quatro pedaços, pardo y negro a ocho reales vara, cinquenta y dos reales (Medina de Rioseco, Va-1645)

Jubón y basquiña de esparragón de flores negro y noguerado, aforrado en tafetán atornasolado (Bercial de Zapardiel, Arévalo, Av-1650)

Vnas enaguas de esparragón tornassoladas, en veinte reales (Pinto, M-1653)

Unas polleras de esparragón de seda con çinco galones de oro (Badajoz, 1653)

Y asimismo le entrega vn auito de esparragón noguerado y negro, cortado, tasado en trezientos y zinquenta reales (Jaén, 1650)

Vnas naguas de esparragón celeste, cinquenta reales [...] Vna basquiña de esparragón obscuro, cinquenta reales (Sevilla, 1745)

Vnas faldillas de esparragón berde, con tres guarniciones de oro fino, en çien reales (Torre Cardela, Gr-1661).

El $D E C H$ lo recoge como derivado de espárrago, del latín ASPARAGUS y, revisados los repertorios lexicográficos, esta voz no aparece hasta 1787 en el Diccionario de Terreros y Pando como «especie de tela de lana», quien lo documenta en Las Ordenanzas de los cinco Gremios Mayores de Madrid; y en 1791 la Academia especifica un poco más: «exido de seda que forma un cordoncillo mas doble y fuerte que el de la tercianela».

\footnotetext{
${ }^{9}$ Dirección General de Rentas, Relación que comprende todos los tejidos de lana, 1780. Archivo de Simancas, DGR, 2. ${ }^{a}$ Remesa, Leg. 4925.
} 
De la variante con aféresis parragón, nuestra base de datos CorLexIn sí nos facilita unas pocas ocurrencias, todas en inventarios andaluces:

Yten, otro jubón de parragón de muger, en quatro reales (Huelva, 1634)

Un jubón de parragón negro, en quarenta reales. Una pollera de parragón, con dos guarniçiones, en çiento y veinte y un reales (Montefrío, Gr-1661)

Ytem, el bestido de parragón de lana de hombre, en los veinte reales de su aprecio (Málaga, 1651)

Vnas enaguas de parragón, çinquenta reales (Bailén, J-1673)

Vna saia de parragón, en nobenta y dos reales. Andújar, J-1665)

Vn jubón de parragón azul, treinta reales (Andújar, J-1665).

En este último inventario andujareño registramos también la variante paragón, con la vibrante simplificada:

Vn cosidillo de paragón azul, dos reales (Andújar, J-1665).

Ni el $C D H$ ni el CORDE recogen ninguna ocurrencia con esparragón o su variante parragón.

\section{ESTAMEÑA}

El $D L E$ lo recoge con la acepción de «tejido de lana, sencillo y ordinario, que tiene la urdimbre y la trama de estambre» y Dávila et alii (2004) especifican «de color negro o pardo, y antiguamente de colores, se usaba para fajas, jubones, faldas, cubrecamas, manteles y hábitos religiosos. A mediados del XIX, la estameña era un tejido de lana pura, ligero, liso, cruzado o no cruzado, crudo o blanco y teñido de negro, pardo, morado y de otros colores [...], sirviendo para distintos usos como vestidos de mujeres, ropajes de jueces, etc.». Y además añaden otra definición: «tela de lana y algodón o de lana y seda, generalmente de color turquí o ceniciento, que se fabricaba casi exclusivamente, mediado el siglo XIX, en el pueblo catalán de Moyá»».

Teniendo en cuenta el elevado número de ejemplos que nos ofrece nuestra base de datos CorLexIn, observamos que este tipo de tejido se utilizaba para la confección de un buen número de prendas de vestir y de ropa de cama, como almilla, basquiña, calçones, calças, capillo, capote, casulla, cobertor, enaguas, jubón, mandil, mangas, mantellina, mantilla, medias, pañal, pollera, pretinilla, rodapiés, ropa de sacerdote, sábana, saya, sobrecama, sotanilla, valones, vestido, zarafuelles, etc.; aunque preferiblemente se usaba para la confección de basquiñas y jubones:

Otra saia de estameña parda (Alzaga, SS-1693)

Ytem, vn cobertor y delantecama y sobremesa de estameña colorada, todo en preçio de çiento y ochenta reales. Dos sobrecamas la vn<a $>$ leonada de labores de manteles y la otra de estameña açul de dos piernas con flocadura de lana colorada, anbas nuebas (Valderas, Le-1647)

Vnos valones de estameña. Vn capotillo de estameña. (Mansilla Mayor, Le-1637)

Un cobertor berde de estameña biexo (Villalobos, Za-1654)

Una cama de tres cortinas de estameña uer[de] usadas (Villalobos, Za-1654)

Vna ropa de saçerdote de estameña negro, mediada. Dos baras de estameña fraylego, nuevo (Autillo de Campos, Pa-1654) 
Ytem, vna casulla berde de estameña y estameña negra por adentro para misas de réquiem (Panticosa, Hu-1688)

Vn jubón y basquiña de estameña plateado (Zaragoza, 1647)

Otro mandil de estameña flariego Aguilafuente (Segovia, 1623)

Una pretinilla de estameña negra, en tres reales (Candeleda, Av-1648)

Un rodapiés de estameña colorada con flueco berde y colorado, en diez reales (Mora, To1637)

Dos sávanas de lienso usadas y otra de estameña, que todas son dies y nueve (Badajoz, 1653)

Y una mantellina garrofada, de estameña (Valverde, Te-1668)

Una basquiña de estameña en veinte y cinco reales (Almansa, Ab-1653)

Vn vestido de estameña platiada, en ciento u cinquenta reales (Argamasilla de Calatrava, CR-1658)

Unas medias de $<e>$ stameña negra en tres reales (Alcantarilla, Mu-1633)

Vna basquiña de estameña nueba, negra, cinco ducados (Baza, Gr-1660)

Yten, se apreció otra saya d<e $>$ estameña picada en quatro ducados (Alcalá de los Gazules, Ca-1642).

Sánchez Orense (2011: 417) considera que la estameña, muy parecida al cordellate, servía para hacer calzas e insiste en que no debía de ser en el siglo XVI una tela ordinaria debido al uso que de él hacían príncipes y nobles, en contra de lo que recogen diccionarios (DLE, DECH, Dávila et alii 2004) y estudios ${ }^{10}$.

En cuanto a la aparición de esta voz a lo largo de la historia, Alfau de Solalinde (1969: 100-101) documenta ejemplos de estameña en el siglo XIII, pero únicamente en la General Estoria (1275):

Et sobresta cobertura echo luego otrossi las cortinas dela estameña.

Esto le hace suponer que la voz estameña habría desaparecido del vocabulario castellano medieval en el siglo XIII, sustituido por voces como burel, sayal o gerga que designaban un 'tejido burdo de lana', y que posteriormente reaparecería en el siglo XIV.

No obstante Martínez Meléndez (1989: 88-93) cree errónea esta hipótesis de Alfau de Solalinde y aporta ejemplos de otras obras del siglo XIII, como Vida de Santa María Egipciaca, Primera Crónica General de España y La Gran Conquista de Ultramar. Considera, por ello, que la voz estameña no desapareció, sino que se mantuvo en castellano desde su origen hasta la actualidad. Asimismo, adelanta la primera aparición a 1215, concretamente a la obra Vida de Santa María Egipciaca:

Non aujan cura destamenyas / nj jazen en lechos nj en camenyas.

También documenta ejemplos en el siglo XIV, concretamente en el Libro de Buen Amor, y en textos no literarios del XV y de principios del XVI. Asimismo en el siglo XVI la documentan en sus respectivos estudios Puche Lorenzo (2003: 134) y Sánchez Orense (2010: 417).

${ }^{10}$ Alfau de Solalinde (1969: 100-101) y Martínez Meléndez (1989: 88-93) consideran que se trata de un tejido tosco, aunque sí reconocen que hubo estameñas de mejor calidad y mayor precio e incluso pintadas en colores. 
En el CORDE los ejemplos más antiguos proceden de General Estoria, pero también facilita ocurrencias del siglo XIV y del XV (Arcipreste de Hita, Cancionero castellano de París, etc.); con un importante incremento en el número de casos a partir del siglo XVI.

Y el $C D H$ propone como documentación más temprana un caso de la Fazienda además de otras ocurrencias de este siglo XIII, también reúne cuatro ocurrencias del siglo XIV y un uso creciente y regular a partir del XV:

Los vieios de la cibdad e los buenos,vestidos d'estamennas (Almerich, La fazienda de Ultra Mar, c1200).

Etimológicamente, es esta una voz patrimonial que procede de TEXTA STAMǏNĚA 'tejidos de estambre, filamentosos', plural de TEXTUM STAMǏNEUM, neutro del adjetivo STAMINNEUS, derivado de STAMEN, -ĨNIS $(D E C H)$. Nebrija ya lo recoge en su Vocabulario español-latino de 1495 como TEXTUM FLAMINEUM, pero no será hasta 1732 en el Diccionario de Autoridades cuando se ofrezca una definición detallada: «Texido de lana assi dicho por ser la urdimbre y la trama toda de estambre».

Desde un punto de vista diacrónico, estameña conoce un uso importante desde época bien temprana, con un repunte en el número de ocurrencias a partir del siglo XVI que se mantendría en el XVII, para luego ir disminuyendo, aunque no sea voz completamente desaparecida.

\section{FILADIZ}

El término filadiz está recogido en el $D L E$ como «seda que se saca del capullo roto y resulta menos estimada» y Dávila et alii (2004) se suman a la definición que aparece en el Diccionario de Autoridades e incluyen también la variante esfiladiz como «filoseda de calidad inferior por separarse fácilmente del capullo».

Nuestra base de datos CorLexIn nos facilita un buen número de ejemplos distribuidos de norte a sur en la zona oriental de la península. De esta documentación podemos deducir que este tipo de tela se utilizaba para la confección de ropa de vestir y ropa de hogar:

Yttem, vna basquiña de raja leonada guarnecida con pasamano de ylo de filadiz (Tudela, Na-1641)

Seis pieças betas estrechas de filadiz de Xátiua (Teruel, 1625)

Una sobremessa de filadiz y cáñamo, con franja de filadiz de pagizo (Teruel, 1677)

Y vn jubón de filadiz leonado y estanbre negro con botones de plata (Albacete, 1642)

Otra vasquiña de filadiz verde y colorado con pasamanos, en ochenta y ocho reales. Otra ropa de filadiz negro con pasamanos, en sesenta y seis reales (Sax, A-1639)

Yten, vnas ennaguas de filadiz y lana açul y colorado, nuebas, en sessenta y seis reales (Sax, A-1661)

Otro cubertor de filadiz y lana con billeute, en nobenta y seis reales (Sax, A-1661)

Ytem, vn guardapié de filadiz y estambre con guarniçiones negras, en veinte y ocho reales (Sax, A-1661)

Un jubón de tela de filadiz y estanbre (Cieza, Mu-1661)

Seis cojines de tela de filadiz rosada poblados de lana en ziento y zinquenta reales (Totana, Mu-1659)

Yten, otro xubón de filadiz y negro, bueno, en dos Ducados (Serón, Al-1659). 
Filadiz se recoge ya en el Diccionario de Autoridades (1732), donde se ofrece una amplia definición descriptiva: «la seda que se saca del capullo roto, ya sea por haver salido dél el gusano convertido en palóma, por estar baboseado por defuera de la palomilla que salió de otro, ó por haver muerto el gusano antes de perficionarle: el qual no se puede hilar con los demás en la caldera de hilar seda, y se beneficia limpiandole y cociendole en xabó, y despues se lava con agua clara, y se hila».

En el $D E C H$ hallamos el término castellano hiladizo, derivado de hilar, el aragonés feladiz 'trencilla' y filadiz, que considera probablemente un catalanismo murciano; lo que explicaría la distribución más oriental de nuestros ejemplos.

El $C D H$ documenta solo dos ocurrencias, una con filadiz y otra con filaiz, ambas en la misma obra:

Filadiz. Seda sacada del capillo roto. Hácense de ella algunas telas para pañuelos y colgaduras (Javier Fuentes y Ponte, Murcia que se fue, 1872)

Y en la mano traia un pañuelo de filaiz (Javier Fuentes y Ponte, Murcia que se fue, 1872).

El CORDE solo registra un único ejemplo de hiladizo y otro de filaiz ${ }^{11}$, recogido también en el $\mathrm{CDH}$ :

Cinco cintas anchas de cuero, labradas de hiladizo de colores, con sus bolsas y esqueros (Francisco López de Gómara, Segunda parte de la Crónica general de las Indias, 1553).

El CorLexIn solo facilita un caso de hiladizo ${ }^{12}$ y no incluye filaiz:

Ocho tocados hiladiços a seys reales cada uno, son quarenta y ocho (Albalá, Montánchez, Cc-1661).

Finalmente, la voz filadiz, que no aparece registrada en el medievo - ni Martinez Meléndez (1989) ni Alfau de Solalinde (1969) la incluyen en sus estudios — parece que conoció un uso muy restringido en el espacio y en el tiempo, como hemos señalado.

\section{FILEILE}

El $D L E$ recoge filelí y la variante fililí con dos acepciones: «tela muy ligera de lana y seda que se solía traer de Berbería» y también coloquialmente «delicadeza, sutileza, primor de alguna cosa»; Dávila et alii (2004) registran las variantes fileile, filelle, filieile, que designan «tejido solo de lana y de lana mezclada con seda» y filali, fileli como «tela de lana muy ligera, delgada, mezclada con hierba o con seda, que se traía de Berbería». Y finalmente Terreros y Pando (1787) añade filelí a la que algunos dice- llaman filela.

Nuestra base de datos CorLexIn nos proporciona unos pocos ejemplos con la variante fileile localizados en el centro y sur peninsular:

Calçones, ropilla y capote de fileile carmesí (Zaragoza, 1647)

Ferreruelo, ropilla y enaguas de luto de fileile (Zaragoza, 1647)

Vn cuerpo de jubón con mangas de fileile negro (Zaragoza, 1647)

\footnotetext{
${ }^{11}$ Terreros y Pando (1786) incluye también la variante filaiz.

${ }^{12}$ No obstante la voz hiladizo también puede hacer referencia a 'lo que se puede hilar'.
} 
Taalí y cinto de fileile negro (Zaragoza, 1647)

Yten, más treinta y nueue baras de phileile angosto en una pieça y un pedaço, a cinco reales vara, monta ciento y nouenta y cinco reales (Medina de Rioseco, Va-1645)

Dos ropas pequeñas de niñas, la vna de bayeta, la otra de fileyle (Madrid, 1649)

Vna basquiña de fileyle forrada en tafetán (Madrid, 1649)

Vna ropa y basquiña de fileyle negro aforrado en tafetán (Madrid, 1650)

Vn ferreruelo de paño de Segouia. Más, otro de fileile negro (Sevilla, 1650).

Ya Covarrubias (1611) define filelí como «cierta tela delgada, hecha así a filo, que traen de Berberia» y el Diccionario de Autoridades (1732), como «tela de lana delgada, mezclada con hierba, que se solía traer de Berberia. Trahe esta voz Covarr. En su Thesoro»; también incluye la voz filili como «delicadeza, sutileza, ò primór de alguna cosa; y assi se dice que una Dama está de fililí. Parece diminutivo de Filis».

No es esta voz patrimonial, pues procede del árabe hispano filāll 'perteneciente a Tafilelt (Tafilete)', ciudad de Berberia (Marruecos), donde se hacía esta tela fina para albornoces. El $D E C H$ considera que la primera documentación es de1573.

El $C D H$ nos proporciona un único ejemplo de fileli:

Item, que ninguno traiga vestido de raja, seda, ni de chamelote, lanilla, burato, media seda, filelí, ni otro género de seda so pena que si lo trajere lo pierda, y de seis días de cárcel, y permítese que se puedan traer jubones, y gregüescos de chamelote, o lanilla siendo negros (Estatutos hechos por la muy insigne Universidad de Salamanca, 1594).

$\mathrm{Y}$ en el CORDE hallamos un único caso moderno, del siglo $\mathrm{XX}$, con la variante filili como 'agudeza, sutileza':

Cuidemos por eso que en nuestras burlas haya rodorín, eso que antes se llamaba busilis, intríngulis, filili: agudeza, chiste o retruécano (Gómez de la Seran, Automoribunda, 1948).

Finalmente y en este punto, es factible concluir que la voz fileile nunca se habría generalizado y su uso sería poco extenso geográfica y temporalmente.

\section{FILIPICHÍN}

El $D L E$ recoge esta voz con la acepción de «tejido de lana estampado» y Dávila et alii (2004) la definen como «paño o tejido de lana estampada, a modo de camelotón, que tenía unas labores hechas con prensa, de origen desconocido, que vendían los gremios de Madrid».

Los ejemplos que obtenemos a partir del CorLexIn se distribuyen fundamentalmente por zonas de la Meseta y con algún caso en inventarios andaluces:

Vna loba de philipichín negra, en honçe reales y medio, a luego pago (Burgo de Osma, So-1640)

Veinte y nueue baras y media de filipichín angosto en dos pedazos, a tres reales y medio bara (Medina de Rioseco, Va-1645)

Vn bestido pequeño de filipichin berde para vna niña en veinte y quatro reales (Mora, To-1637)

Otro jubón y basquiña de filipichín, traydas, con vnas enaguas açules, traídas (Atienza, Gu-1641)

Yten, vnas polleras de philipichín en ocho ducados (Huelva, 1676) 
Yten, nueue baras de philipichín en rodapiés y sobrecamas que costó onze ducados (Huelva, 1676).

También hallamos la variante con disimilación vocálica felipichín:

Dos varas de phelipichín nuevo (Herrera de Valdecañas, Pa-1700)

Yten, se remató un cuerpo de felipechín, negro, en María Calbo, muger de Françisco Ybáñez, en ocho reales (Ólvega, So-1638)

Yten, una saya de felipichín morado, colchada, bale çiento y beinte reales (Cuenca, 1631) Yten, cada uara de felipichín, a seis reales de uellón (Huelva, 1691).

Nosostros creemos que el término de origen sería filipichín ${ }^{13}$ que es la que se halla recogida en el $D E C H$ y en los diccionarios académicos, desde el Diccionario de Autoridades hasta hoy, además es la forma que aparece en el CORDE y en la mayoría de nuestros ejemplos. Por ello, consideramos que felipichín es variante minoritaria, que, al menos en una ocasión, alterna con la voz patrimonial en el mismo documento: «un vestido pequeño de filipichín verde» frente a «un faldelín de felipichín encarnado» (Mora, To-1637), donde la disimilación puede deberse a cuestiones de fonética sintáctica en un intento de evitar la sucesión de -í- en faldelín de filipichín.

En el $C D H$ y en el CORDE, hallamos cuatro ejemplos, tres del siglo XIX y uno del $\mathrm{XX}$. En ambas listas solo una ocurrencia pertenece a un inventario español, la más temprana recogida en el $\mathrm{CDH}$ :

Colchas de filipichin,/ Casacas de filoseda (Manuel Bretón de los Herreros, Poesías, 1828-1870).

De ambas bases de datos la ocurrencia más antigua es esta:

Y tanto que vueseñoría a ferió una basquiña de filipichín y un refajo redondo (Ricardo Palma, Tradiciones peruanas, segunda serie, 1874).

La primera definición lexicográfica se halla en el Diccionario de Autoridades (1732): «especie de texido de lana à modo de chamelotón, que tiene unas labores hechas con prensa [...] Cada vara de filipichines de colores a diez reales». El DECH señala que la primera documentación procede de la Pragmática de 1680, tal y como se recoge en Autoridades. No obstante, podemos adelantar esa fecha a 1631 con este ejemplo facilitado en el CorLexIn:

Yten, una saya de felipichín morado, colchada, bale çiento y beinte reales (Cuenca, 1631).

Finalmente, aunque el $D E C H$ advierte que su origen es desconocido, quizá podríamos pensar en un derivado a partir de hilo.

\section{GORGORÁN}

El término gorgorán, y la variante gorguerán, están recogidos en el $D L E$ como «tela de seda con cordoncillo, sin otra labor por lo común, aunque también lo había listado y realzado» y Dávila et alii (2004) concretan que la voz gorgorán hace referencia a

${ }^{13}$ Morala (2012: 561) también menciona las voces filipichín y felipichín, aunque considera que la voz patrimonial es felipichín. 
«telas góticas, por lo general, procedentes de Holanda, aparecen a menudo mencionadas en la documentación de las Tarifas de la Bolla catalana ${ }^{14}$ en la segunda mitad del siglo XVII y en los inventarios de tiendas de tejidos catalanes del XVIII». En cuanto a la procedencia de esta tela, para Terreros y Pando (1787) el gorgorán de Nápoles y el gorgorán de Tours son los más estimados.

Los ejemplos que nos facilita el CorLexIn son numerosos y dan fe de un buen número de variantes en el uso:

Yten, otro vestido de gorgorán de cordoncillo con vn herreruelo de tela de zeuolla, bueno (Vitoria, 1638)

Yten, ropa, y basquiña y jubón de gorgorán negro (Ciudad Rodrigo, Sa-1633)

Una vasquiña de gorgorán negro forrada en olandilla (Alburquerque, Ba-1683)

Vna saia de gorgorán, en treinta reales (Argamasilla de Calatrava, CR-1658)

Vn jubón de gorgorán nuevo, en ocho ducados (Atienza, Gu-1641)

De vnas mangas de gorgorán pajiço y leonado con vna caracolica de oro, en veinte y quatro reales (Atienza, Gu-1640)

Vna mantellina de gorgorán negra nueua aforrada en baieta berde con dos passamanos, sesenta reales (Guadalajara, 1625)

Vn rebociño de gorgorán atirelado aforrado en bayeta colorado, en sesenta reales (Cebreros, Av-1652)

Yten, vna sotanilla de gorgorán liso, vieja (Cuenca, 1622)

Vna sotanilla de gorgorán, de clérigo, traída (Pinto, M-1653)

Vn reboçiño de gorgorán aforrado en bayeta negra (Illescas, To-1626)

Vnos calçones de gorgorán pardo (Toledo, 1616)

Más, unos cuerpos de gorgorán i unas mangas de grana (Jaraíz de la Vera, Cc-1663)

Vn niño Jesús con su ropita y balona y sus bestiditos de gorgorán, tasado todo en tres ducados, con los vestidos (Plasencia, Cc-1629)

Un coletillo de gorgorán negro (Moratalla, Mu-1637)

Vn xubón de gorgorán de muxer nuebo de la tela y labor de la ropa, guarnezido en vn galón, en quatro ducados (Serón?, Al-1659)

Yten, vna basquiña y jubón de gorgorán de seda, noguerado, a medio traer (Almería, 1659).

El $D E C H$ señala que gorgorán, y el anticuado gorguerán, proceden del inglés grogoram (siglo XVI) y este del francés antiguo grosgrain 'grano grueso'. Debido, pues, a este origen extranjero era fácil que proliferasen variantes fonéticas y ortográficas como las documentadas gorguerán, gorgerán, gorgarán o gorbalán:

Primeramente vna capa corta de gorguerán de Ytalia, en çien reales (Bilbao, 1645)

Calzón, ropilla y ferreruelode gergueta pasa aforrado en gorguerán labrado y jubón de gorgarán (Vergara, SS-1632)

Un jugón de gorgueram biejo contenido en el dicho imbentario (Vitoria, 1638)

Vn bestido de gorguerán de aguas, de lana cauellada con alamares (Zaragoza, 1647)

Vn reboçiño de gorguerán açul y paxiço con passamanos de plata y oro que pareçe falso (Valderas, Le-1647)

Vna sotanilla de gorguerán viexa, labrada (Villamuñío, Le-1633)

${ }^{14}$ Tarifas de la Bolla y dels preus de les teles, y altres sorts de robas y mercaderies, que entren en lo Principat de Cathalunya y Comtats de Roselló y Cerdanya..., Barcelona 1624, 1636, 1656 y 1668. 
Vn bestido de gorguerán pardo, passado (Madrid, 1650)

Vnos cuerpos de gorguerán con terçiopelo uerde, ueynte reales (Albalá, Montánchez, Cc-1661)

Un vestido de gorguerán negro de muger, un vestido de gorguerán negro de muger (Alburquerque, Ba-1645)

Vn bestido de gorguerán de onbre, traído, en zien reales (Jaén, 1650)

Vn jubón de gorguerán negro vsado en ventidós reales (Sax, A-1639).

De la variante gorgerán solo recogemos ejemplos en Cantabria y Teruel:

Más se puso por ynbentario un corte de jubón de gorgerán labrado de colores con un pedazo de tafetán berde (Cacicedo, C-1635)

Item, vn vestido entero de gorgerán de muestras de color, con su mantellina de lo mismo (Teruel, 1622)

Iten diez uaras de gorgerán de muestras de color (Teruel, 1622)

un calçón de gorgerán de muestras negro estimado en trecientos sueldos (Teruel, 1622).

Y de gorgarán, en el primer ejemplo combinado con gorguerán, hallamos unos pocos casos en Guipúzcoa, Vizcaya y Ávila:

Calzón, ropilla y ferreruelo de gergueta pasa aforrado en gorguerán labrado y jubón de gorgarán (Vergara, SS-1632)

Un ferreruelo de gorgarán negro forrado en felpa y sotanilla sin mangas, de gorgarán (Vergara, SS-1632)

Vn ropón de gorgarán, çiento y sesenta reales (Bilbao, 1645)

más vna armilla de gorgarán negro (Deusto, Bi-1643)

Unos cuerpos biejos de gorgarán (Bercial de Zapardiel, Arévalo, Av-1650).

La variante gorbalán solo la hemos registrado en una ocasión:

Una sotana de gorbalán negro con sus mangas, todo biejo (Montefrío, Gr-1662).

Finalmente, El CorLexIn nos proporciona cuatro ejemplos de gorbarán en tres inventarios mexicanos de 1622 y 1623 :

Yten, otro bestido de gorbarán frailesco, picado, çient pessos (Ciudad de México, México, 1623)

Sobre tres baras y media de gorbarán negro (Ciudad de México, México, 1622).

Bastardín (2012: 48) también halla esta variante, que considera poco documentada, en inventarios gaditanos del XVII:

Una ropilla de gorbaran (Archivo Histórico Provincial de Cádiz).

Todos estos testimonios de las diversas variantes son interesantes y dan fe de cómo el término extranjero se adaptó en español mediante realizaciones fonéticas diversas que tratarían de imitar la voz de origen grosgrain.

Diacrónicamente no parece esta voz muy antigua a la luz de los ejemplos proporcionados, el $D E C H$ considera que la primera documentación se halla en Guzmán Alfarache (1599). Los datos facilitados por el CORDE confirman que casi todos los ejemplos son del siglo XVII, que la variante más temprana es gorgarán —en 1599- y la que tiene mayor número de ocurrencias, gorgoran: 
Terciopelo, raso, damasco, tafetán, rizo, gorgarán, chamelote, lanillas para vestiros a vos y a mí (Diálogos de John Minsheu, 1599)

Una saya entera, con manga redonda de gorgoran verdemar, bordado todo el campo de oro y plata muy delgado (Relación y memoria de las joyas de Ana de Austria, 1615)

Yten, otro jubon de gorgoran celeste, en 55 (Inventario y valoración de bienes, de Jerónimo López, 1615).

En cambio en el $C D H$, las variantes más tempranas son gorgerán y gorguerán, documentadas en 1609 y 1612, respectivamente; y la más frecuente y mayoritaria en el siglo XVII es gorgorán:

Qual de la tela, y gorgeran cubierto,/ O el terciopelo conuertido en raso (Lope de Vega, Jerusalén conquistada, 1609)

Un herreruelo de gorgueran muy bueno, suyo, y casi nuevo, con su ropilla y calzones (Miguel de Castro, Vida de Miguel de Castro, c1612)

Una casulla de gorgorán negro, labrado, con estola y manípulo de lo mismo y çenefa de terçiopelo negro (Inventarios Reales. Bienes muebles que pertenecieron a Felipe II, $c 1600)$.

En el NTLLE solo hallamos gorgorán y gorguerán, definido por vez primera en el Diccionario de Autoridades (1734) como «tela de seda con cordoncillo».

En resumen, este término se documenta desde fines del siglo XVI, con un aumento en el número de ocurrencias en el XVII y una disminución notable en las centurias siguientes.

\section{PERPETUÁN}

Se trata de una «tela de lana, basta y muy tupida y duradera» según el $D L E$, acepción que coincide con la de Dávila et alii (2004) «tela de lana, basta y fuerte, muy tupida y duradera. Se le daba ese nombre por ser muy fuerte y de mucha duración».

El CorLexIn reúne un buen número de ocurrencias localizadas de norte a sur peninsular:

Tres cortinas, las dos de perpetuán y otra de cordellate verde (Vergara, SS-1632)

Yten se ynbentarió un ferreruelo de perpetuán negro nuevo (Cacicedo, C-1635)

Vna sotanilla de perpetuán, traída (Villamuñío, Le-1633)

Vna montera de color, de perpetuán (Villamuñío, Le-1633)

Un bestido de perpetuán, basquiña y jubón (La Puebla de Arganzón, Bu-1620)

Otro ferreruelo de perpetuán, en cinquenta reales (Albacete, 1642)

$\mathrm{Y}$ vn jubón de perpetuán plateado, en çien reales. Vna basquiña de perpetuán negro con su jubón de lo mismo, en çien reales. (Albacete, 1642)

Vnas mangas de perpetuán, en seis reales (Olmeda del Rey, Cu-1625)

Dos ropillas, vna de perpetuán y otra de raso viejo (Toledo, 1616)

Item, otro ferreruelo de perpetuán negro estimado en ciento y (tachado: cinque) sesenta sueldos (Teruel, 1622)

Vna basquiña de la misma color verde, perpetuán, en sesenta y seis reales (Sax, A-1639)

Otra saya de perpetuán leonado traída, con su jubón viejo (Plasencia, Cc-1629)

Dos basquiñas de perpetuán, en siete ducados. Vn jubón de perpetuán, en dies y seis reales (Huelva, 1617). 
También Bastardín (2012: 47) recoge ejemplos de perpetuán en particiones de bienes gaditanas del siglo XVII: «Siete piezas de perpetuan de colores» y «Otro pedazo de perpetuan».

En 1737 el Diccionario de Autoridades ofrece una detallada definición: «cierto género de tela de lana, a quien se le da este nombre por ser mui fuerte y de mucha duración»; unos años antes, en 1705, Sobrino en su Diccionario nuevo de las lenguas española y francesa, ya contemplaba la definición textil de esta voz «espece de sarge comme de la Tiretaine».

Diacrónicamente no parece ser voz existente en el medievo pues no tenemos datos que lo confirmen y tanto el CORDE como el $C D H$ recogen como ejemplo más antiguo este del siglo XVII:

Tenía otro que hice de perpetuan, de color llano, para galera (Miguel de Castro, Vida de Miguel de Castro, c1612).

Y la forma con tilde perpetuán presenta una primera documentación en 1614:

Le suplica en un papel le regale con no sé qué alcorças, en cambio de ocho varas de un picotillo famoso o perpetuán vareteado que le embía (Alonso Fernández de Avellaneda, Don Quijote de la Mancha, 1614).

Con toda la nómina de ejemplos facilitada por las diferentes bases de datos y autores, parece que la época de máximo uso es el siglo XVII, ni antes ni después hallamos documentación que nos permita de momento justificar un uso más prolongado en el tiempo.

El $D E C H$, que no especifica la fecha de la primera documentación, considera que esta voz patrimonial deriva de PERPĚTǓUS 'continuo, sin interrupción' 'que dura siempre'.

\section{SEMPITERNA}

El DLE define sempiterna como «tela de lana, basta y muy tupida, que se usaba para vestidos» y Dávila et alii (2004) como «tejido de lana o sarga, cruzado no cortado, apretado, basto y de bastante cuerpo, que evoca la solidez. Muy popular en el siglo XVIII, lo usaban las mujeres pobres para vestirse y hacer jubones y guardapiés. Pudo llamarse así por ser mucha su duración». Es voz que deriva del latín SEMPITTĚRNUS $(D E C H)$.

Sempiterna aparece con frecuencia en los inventarios del siglo XVII a la luz del gran número de ejemplos que nos facilita el CorLexIn:

Tres sobrecamas coloradas al parecer de sempiterna (Ribadesella, Ast- 1681)

Vna saia de sempiterna de color [a]-musco oscuro (Alzaga, SS-1693)

Yttem, quinze baras y media de sempiterna negra (Tudela, Na-1641)

Más un jubón de sempiterna hazul andado (Lumbreras, LR-1688)

Vna lova de senpiterna viexa son sus mangas (Cifuentes de Rueda, Le-1648)

Vn guardapiés encarnado de senpiterna, bueno (Herrera de Valdecañas, Pa-1700)

Vna ropa de senpiterna negra, buena, en tres ducados (Pinto, M-1653)

Vna basquiña y jubón de sempiterna color cauellado, en diez ducados (Mora, To-1637)

Dos manteos de paño veinte y dozeno negro. Un manteo de bayeta de senpiterna (Alburquerque, Ba-1645)

Una casaca de senpiterna negra (Alburquerque, Ba-1683) 
y una pollera de senpiterna guarneçida (Cieza, Mu-1661)

Yten, vna basquiña de senpiterna de color, en seys ducados (Lebrija, Se-1641)

Vn cobertor de senpiterna colorada con su pernesuela de lo mismo con su guarnisión de oro, todo en ochenta reales (Arcos de la Frontera, Ca-1666)

Vnas naguas de sempiterna encarnada con franxas. Ocho varas de senpiterna encarnada, digo destameña de Ynglaterra (Huelva, 1673)

Yten, vna cortina de sempiterna encarnada en doze reales (Huelva, 1688)

Vna mantellina de sempiterna, encarnada con tafetán amarillo, en quarenta y quatro reales (Montefrío, Gr-1661).

Muy excepcionalmente, documentamos la variante sinpiterna, con asimilación de la vocal inicial:

Un jubón de sinpiterna berde con mangas de raço negras (Alburquerque, Ba-1683).

Por el contrario su uso en otras bases de datos no parece muy documentado, tanto el CORDE como el $C D H$ reúnen poquísimas ocurrencias de esta voz y proponen como ejemplo más temprano el siguiente de mediados del XVII:

Enaguas de sempiterna encarnada con siete vueltas de puntas negras de telarejo (Juan de Zabaleta, El día de fiesta por la tarde, 1660).

No obstante podemos adelantar la fecha a 1637, atendiendo a la nómina de ejemplos facilitada por nuestro corpus:

Vna basquiña y jubón de sempiterna color cauellado, en diez ducados (Mora, To-1637).

Y la lexicografía es más tardía, pues no será hasta 1706 cuando Stevens en su obra A new Spanish and English Dictionary nos proporcione la primera definición: «a Stuff call'd Perpetuana, Ell wide. So call'd, because very lafting» y en 1788 Terreros y Pando en su Diccionario castellano especifica «Especie de tela. Fr. Sempiterne, perpetuanne, y según Sobrino, serge».

\section{TABí}

Es voz que designa «tela antigua de seda, con labores ondeadas y que forman aguas» $(D L E)$ y más concretamente «tafetán de seda, prensado, que se usaba antiguamente, cuyas labores sobresalían formando aguas y ondas como el moaré y que se fabricaba en las ciudades italianas de Florencia, Venecia, Nápoles, Luca y Verona» y también «géneros ligeros de seda o de seda y algodón elaborados según una técnica originaria de Bagdad (Toniolo)» (Dávila et alii 2004).

No parece voz muy usual a la luz de los pocos ejemplos documentados ${ }^{15}$ :

Yten, vna casulla, estola, manípulo y frontal de tabí de agoas blanco con flores de colores, bordado sobre tela de plata, que vino de Ytalia para la capilla de los señores condes (Oñate, SS-1617)

Item, una sotanilla de tabí negro de hombre estimada en quinientos sueldos (Teruel, 1622)

${ }^{15}$ Algunos de los ejemplos facilitados por el CorLexIn proceden de documentos notariales hispanoamericanos de Ciudad de México (1622), Guatemala (1623), Potosí (Bolivia, 1625), Choconta (Colombia, 1633) y La Plata (Bolivia, 1703). 
Ytem otra casulla de tabi de aguadas blanco con galón de oro (Panticosa, Hu-1688)

Vn jubón de taui dorado (Sevilla, 1650)

Ytten, otro telar de taui con su abiadura de seda y sus aynas, en quatroçientos reales (Sevilla, 1669)

Yten, vna basquiña de tabí noguerado, de aguas, guarneçido de puntas negras, apreçiado en treçientos y treinta reales (Cádiz, 1654)

Yten, vn corpiño de raso asul y plateado guarnesido de puntas y otro de tabi asul guarnesido con franja de plata, anbos en dies pesos (Cádiz, 1665).

El $D E C H$ considera que procede del italiano tabì y este del árabe attābî por fabricarse en Al-Attābîya, suburbio o barrio de tejedores de Bagdad; y propone como primera documentación la fecha de 1604, que el CORDE y el $C D H$ adelantan a 1600 con este ejemplo:

Capa con su capilla y pectoral, cuerpos y cenefas de tabi blanco de oro (Inventarios Reales. Bienes muebles que pertenecieron a Felipe II, 1600).

Dávila et alii (2004) mencionan que ya en el siglo XIII se cita un tabí en seda y algodón, pero no especifican en qué documento. Alfau de Solalinde (1969) y Martínez Meléndez (1989) no lo recogen en sus estudios sobre léxico medieval.

En el Diccionario de Autoridades (1739) aparece la primera definición: «cierto género de tela que se usaba antiguamente, como tafetán gruesso prensado, cuyas labores sobresalían haciendo aguas, y ondas».

\section{TIRELA}

Dávila et alii (2004) consideran que se trata de un «tejido mencionado en la documentación de Tarifas de la Bolla catalana en la segunda mitad del siglo XVII entre los de seda como tirela de terciopelo o tirela de vellut. Tela listada».

Los ejemplos que nos proporciona el CorLexIn son los siguientes:

Yten vna almilla de tirela, 100 reales (Bilbao, 1643)

Un jubón de tirela con mangas nuebas. Unos calçones de tirela negros (Vergara, SS1632)

Yten se pusso por ynbentario un bestido de color berde, ferreruelo, calçón y ropilla, con sus mangas de tirela verdes (Cacicedo, C-1635)

Tres baras y tercia de tirela de riuetillo negra, a veinte y ocho reales (Medina de Rioseco, Va-1645)

Vn jubón de tirela aforrado en fustán (Nava del Rey, Va-1648)

Yten vnas mangas de tirela negra, veinte y quatro reales (Mora, To-1637)

Vna vasquiña de tirela negra (Logrosán, Cc-1668)

Vn corpiño de tirela guarneçido con pasamanos, en tres ducados (Plasencia, Cc-1629)

Vn bestido çayno de raxa de paño aprensado, ferreruelo, calçones, ropilla, y jubón de bonbasí con mangas de tirela negra (La Roda, Ab-1643)

Yten, vn jubón de mujer de tirela negro con botones de bronze dorados, en veinte ducados (Cádiz, 1635)

Más una saya de paño vitorio aforrada en tafetán açul con su ribete de tirela apreçiada en nuebe ducados (Cádiz, 1639)

Yt, vna camisa de morlés con su tirela de red, en tres pessos y medio (Cádiz, 1665).

También registramos la variante tirrela en el inventario vallisoletano ya mencionado: 
Primeramente, veinte baras de tirrela negra vandeada, thasada a treinta reales vara (Medina de Rioseco, Va-1645).

Y Morala (2015: 167) recoge tirelón, como derivado de tirela, aunque advierte que no aparece en los diccionarios:

Vn jubón de tirelón nuebo negro (Cádiz, 1639).

Asimismo, Bastardín (2012: 51) reúne otros dos casos más en inventarios gaditanos del siglo XVII: «Vn pedazo de tirelon negro» y «otro pedazo de tirellon negro».

Por su parte el CORDE y el CDH proporcionan unos pocos ejemplos, todos registrados en textos del siglo XVII, el más temprano es de 1617 y el más tardío de 1645:

Un jubon de tirela negro [...] Yten, unos balones de tirela negros (Inventario de los bienes de Jorge de Santa María racionero de la Santa Iglesia de Toledo, 1617).

Aparece esta voz en el Diccionario de Autoridades (1739) como 'tela listada'. Y en cuanto a su origen, aunque no la recoge el $D E C H$, es fácil suponer que se trata de un derivado de tira, con clara referencia a un tipo de tela que simularía listas o tiras.

\section{CONCLUSIONES}

Como hemos podido ver en este tipo de documentos notariales aparece un registro lingüístico que a veces no coincide con el de la obra culta, pero que resulta imprescindible porque da buena cuenta del uso real de la lengua de cada época. Es precisamente en ese registro donde es frecuente encontrar un elenco variado de voces que designan, por ejemplo, tipos de texturas de las ropas que se inventarían.

La mayoría de esas voces tienen una procedencia extranjera, es el caso de burato, chamelote, crea, gorgorán o tabí en ocasiones se trata de la adaptación de un topónimo, como en anascote o fileile, en otros casos la voz es un adjetivo patrimonial que alude a alguna característica de la tela o del uso, como sempiterna, perpetuán, tirela o beatilla.

También observamos que muchas de estas palabras han desaparecido, pues la vida de estas está también condicionada por las modas y avances tecnológicos que tienen en su poder mantener los tejidos y voces, como en el caso de estameña, o hacer desaparecer una tela y por ende la palabra que la identifica, como ocurrió con anascote, burato, beatilla, chamalote, crea, filipichín, tabí, tirela, etc. De todos los términos que hemos documentado en el siglo XVII, muy pocos se registran en el siglo XVI, alguno sí aparece en el XV y solo en dos casos existe documentación que confirma el uso en los siglos XIII y XIV. En la mayoría de los casos se trata de palabras de corta vida, pues más allá del XVII, casi todas están en franco retroceso.

En este punto, basten estas palabras de Casares (1992: 283) para poner de manifiesto la idea de la fugacidad de estas voces condicionadas por factores extralingüísticos:

Sin salir del Quijote encontramos los siguientes nombres de telas también olvidados: velarte, velludo, sinabafa, angeo, sirgo, cordellate, palmilla, camelote, marisca, platilla, gorbián, anascote, etc. Seguramente pasan de un centenar las denominaciones de antiguos tejidos que figuraban en el Diccionario de Autoridades y que no significan ya nada para las últimas generaciones. 


\section{REFERENCIAS BIBLIOGRÁFICAS}

Alfau de Solalinde, Jesusa (1969): Nomenclatura de los tejidos españoles del siglo XIII, Madrid, Anejos del Boletín de la Real Academia Española.

BASTARDín, Teresa (2012): "Léxico de los Siglos de Oro en documentos notariales: las particiones de bienes del Archivo Histórico Provincial de Cádiz», Cuadernos del Instituto de Historia de la Lengua, 7, pp. 31-59.

BERNIS, Carmen (1962): Indumentaria española en tiempos de Carlos V, Madrid, Instituto Diego Velázquez, CSIC.

CASARES, Julio (1992): Introducción a la lexicografía moderna, Madrid, CSIC.

CASTRO, Américo (1921): «Unos Aranceles de Aduanas del siglo XIII», Revista de Filología Española, VIII, pp. 1-29.

$C D H$. INSTITUTO DE INVESTIGACIÓN RAFAEL LAPESA DE LA REAL ACADEMIA ESPAÑOLA (2013): Corpus de Nuevo Diccionario Histórico < http://web.frl.es/CCDHE> [octubre de 2016].

CORDE. ReAl ACADEMIA EsPañola: Banco de datos en línea Corpus diacrónico del español $<$ http://www.rae.es $>$ [octubre de2016].

CorLexIn. José Ramón MORALA, dir., Corpus Léxico de Inventarios (CorLexIn), $<$ http://web.frl.es/CORLEXIN.html> [octubre de 2016]

DÁvila, Rosa, M. ${ }^{a}$ Monserrat DuRÁn y Máximo GARCÍA FERnÁndeZ (2004): Diccionario histórico de telas y tejidos, Salamanca, Junta de Castilla y León.

DECH. Joan COROMINAS y José Antonio PASCUAL (1980-1991): Diccionario crítico etimológico castellano e hispánico, Madrid, Gredos.

DLE. REAL ACADEMIA ESPAÑOLA $\left(2014^{23}\right)$ : Diccionario de la lengua española, $<$ http://lema.rae.es/ DLE/> [octubre de 2016]

EGIDO, M. ${ }^{a}$ Cristina (2010): «Léxico de indumentaria femenina y joyas en relaciones de bienes de la Maragatería, Cepeda y Órbigo (León s. XVII)», en Ana M. ${ }^{a}$ Cano, ed., Homenaxe al Profesor Xosé Lluis García Arias, Lletres Asturianes, Anexu 1, Uviéu, Academia de la Llingua Asturiana, I, pp. 95-116.

GARCÍA FERNÁNDEZ, Máximo (2004): «Tejidos con "denominación de origen extranjera" en el vestido castellano. 1500-1860», Estudios humanísticos. Historia, III, pp. 114 144.

MARTínez MelÉndeZ, M. a del Carmen (1989): Los nombres de tejidos en castellano medieval, Granada, Universidad de Granada.

Morala, José Ramón (2010): «Léxico con denominaciones de origen en inventarios del Siglo de Oro», en Rosa Rabadán, Trinidad Guzmán y Marisa Fernández, eds., Lengua, traducción, recepción. En honor de Julio César Santoyo // Language, Translation, Reception. To Honor Julio César Santoyo, León, Universidad de León, I, pp. 385-417.

MorALA, José Ramón (2012): «Alternancias en el vocalismo átono en textos notariales del siglo XVII», en E. Montero, ed., Actas del VIII Congreso Internacional de Historia de la Lengua Española, Santiago de Compostela, Meubook, I, pp. 555-564. 
MoralA, José Ramón (2015): «Los inventarios de bienes y el léxico del siglo XVII en el AHP de Cádiz», en T. Bastardín y M. ${ }^{a}$ M. Barrientos, eds., Lengua y cultura en el Archivo Histórico Provincial de Cádiz, Cádiz, Universidad de Cádiz, pp. 147-174.

PERÉZ TORAL, Marta (2008): «Aproximación sintáctica a la lengua notarial medieval», en C. Company y J.G. Moreno, eds., Actas del VII Congreso Internacional de Historia de la Lengua Española, Madrid, Arco/Libros, pp. 2079-2096.

PERÉz TORAL, Marta (2013): «Marcas de cohesión textualen documentos notariales del medievo asturiano», Archivum, LXIII, pp. 245-274.

PERÉz TORAL, Marta (2015): «El léxico del ganado vacuno en Asturias a partir de textos del siglo XVII y su posible vigencia en la actualidad», Lletres Asturianes, 113, pp. 87109.

PERÉz TORAL, Marta (2017a): «Tejidos y textiles en la vida cotidiana del siglo XVII», Revista de Investigación Lingüística, 20, pp. 195-219.

PÉREZ TORAL, Marta (2017b): «A vueltas con el léxico textil inventariado en el Siglo de Oro», Anadiss, numéro hors-série / mai, In Honorem Doctor Honoris Causa Johannes Kabatek, Editura Universitatii «Stefan cel Mare» din Suceava, pp. 89108.

PuCHE LoRENZO, Miguel Ángel (2002): El español del siglo XVI en textos notariales, Murcia, Universidad de Murcia.

SÁNCHEZ ORENSE, Marta (2008): «Particularidades del léxico de la moda renacentista: dificultades en su análisis», Cuadernos del Instituto Historia de la Lengua, 1, pp. 65-74.

SÁnchez Orense, Marta (2010): «Los nombres de las telas en el siglo XVI», en M. ${ }^{\mathrm{a}} \mathrm{T}$. Encinas et alii, comps., Ars longa, diez años de la AJIHLE, Buenos Aires, Voces del Sur, pp. 413-430

SÁnchez ORENSE, Marta (2012): «Estudio del léxico de la industria textil y de la sastrería en la época renacentista: estructura, contenido y resultados», Interlingüistica, XXII, II, pp. 383-398.

StAlA, Ewa (2014): «Nombres de telas en el Waaren-Lexicon in Zwölf Sprachen de Ph. A. Nemnich (1797)», Revista de Investigación Lingüistica, 17, pp. 191-220.

TORRES FonTES, Juan (1968): «La vida en la ciudad de Murcia en 1442-1444, precios y salarios», Anuario de Historia Económica y Social, I, pp. 691-714.

Vicente Miguel, Irene (2009): «Aproximación al léxico de los tejidos y la indumentaria en documentos notariales medievales», en L. Romero y C. Juliá, coords., Tendencias actuales en la investigación diacronica de la lengua: actas del VIII Congreso Nacional de la Asociación de Jóvenes Investigadores de Historiografía e Historia de la Lengua Española Barcelona, del 2 al 4 de abril de 2008, Barcelona, Universitat de Barcelona, pp. 505-513.

\section{TÍTULO/TITLE}

«El léxico de tejidos en inventarios notariales del siglo XVII» «The tissues lexicon in notarial documents seventeenth century» 
Resumen: En este trabajo analizamos algunas voces pertenecientes al léxico textil que aparecen documentadas en inventarios notariales peninsulares del siglo XVII reunidos en el Corpus Léxico de Inventarios (CorLexIn). En nuestro estudio nos detendremos en la historia lingüística de cada voz textil: su posible origen y motivación, su significado, variantes y extensión diatópica constatada a partir de los ejemplos documentados.

Palabras clave: lexicografía; tejidos; inventarios notariales; siglos de oro.

Abstract: In this paper we analyze some voices belonging to the textil lexicon appering documented in notarial peninsular documents seventeenth century gatered in the Corpus Lexical Inventory (CorLexIn). In our study we will stop in the linguistic history of every textile voice: their possible origin and motivation, their meaning, variants and extension diatopical obsereved from the documented examples.

Key words: lexicography; textil lexicon; notarial documents; golden age. 